\title{
EXPERIÊNCIAS DE INTEGRAÇÃO NA INVESTIGAÇÃO DO TRABALHO DOMÉSTICO - RECONFIGURAÇÃO DO HABITUS CIENTÍFICO
}

Elisa Gomes

Raquel Fera

Dezembro 2009

WP n $2009 / 83$

\section{DOCUMENTO DE TRABALHO}

WORKI NG PAPER

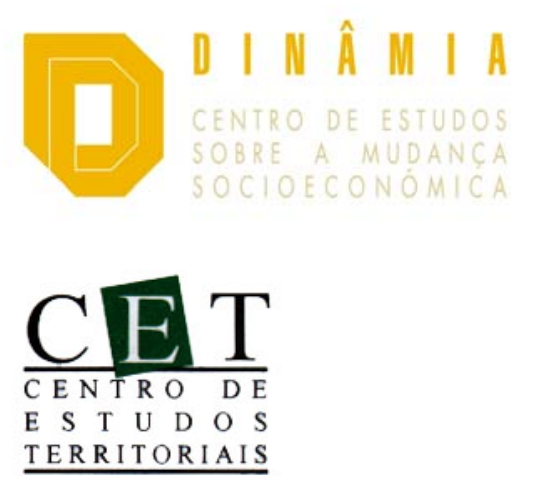

FCT 


\section{Experiências de Integração na Investigação do Trabalho Doméstico - Reconfiguração do habitus científico ${ }^{1}$}

2.2 IMBRICAMENTO ENTRE SISTEMA SOCIAL DINÂMIA E O SISTEMA PSÍQUICO DO SUJEITO DA OBJECTIVAÇÃO

3. PRINCIPAIS TAREFAS

3.1 ESTUDO DE CAMPO - PARTE I

3.2 ESTUDO SOBRE EMPRESAS DE CONTRATAÇÃO DE TRABALHO DOMÉSTICO 10

3.3 ESTUDO DE CAMPO - PARTE II 13

4. CONCLUSÃO 14

5. CRONOGRAMA 14

6. BIBLIOGRAFIA 15

\footnotetext{
${ }^{1}$ Este Working Paper insere-se no âmbito do projecto “Trabalho Doméstico e Trabalhadores domésticos: Perspectivas Interdisciplinares e Comparadas", financiado pela FCT - Fundação para a Ciência e a Tecnologia, Ref. PDDC/JUR/65622/2006.

* DINÂMIA/ISCTE, Lisbon, Portugal.

$\because$ DINÂMIA/ISCTE, Lisbon, Portugal. 


\section{INTRODUÇÃO}

O objectivo deste texto consiste em compreender os processos sociais de integração na investigação por nós experienciados enquanto Bolseiras de Integração na Investigação (BII), estudantes do primeiro ciclo do ensino superior, especificamente nas áreas da Sociologia e Ciências da Educação.

As bolsas em questão foram-nos atribuídas pela Fundação para a Ciência e Tecnologia (FCT) a 2 de Dezembro do ano 2008 e tiveram a duração de 12 meses. O tipo de bolsa que nos foi atribuída, denominada "Bolsa de Integração na Investigação", destina-se a estudantes do primeiro ciclo inscritos em instituições nacionais do Ensino Superior e tem por objectivo "estimular o início de actividades científicas e o desenvolvimento do sentido crítico, da criatividade e da autonomia dos estudantes através da prática da investigação, da aprendizagem dos seus métodos e da participação na vida de instituições de investigação"2.

O projecto de investigação no qual nos integrámos denomina-se "Trabalho Doméstico e Trabalhadores Domésticos: Perspectivas interdisciplinares e comparadas” e tem-se desenvolvido sob a coordenação de Lisa Tortell. Na realização de uma análise que se pretende interdisciplinar, conta-se com a colaboração de uma equipa de especialistas em Sociologia, Direito e Economia. Assim, o objecto trabalho doméstico e trabalhadores domésticos é estudado tendo em conta duas perspectivas, a saber, uma perspectiva socio-jurídica e uma perspectiva socio-económica. Por outro lado, do carácter comparativo deste projecto emerge uma preocupação de internacionalidade, sendo que, para isso, conta com a colaboração de outros países: Brasil, Reino Unido, Nova Zelândia, Índia e, mais recentemente, Moçambique.

O projecto desenvolve-se ao longo de quatro principais etapas. A primeira etapa do projecto consistiu na revisão de literatura nacional e internacional e na realização de formulários a serem preenchidos por todos os países envolvidos no projecto (excepto Moçambique, que entrou mais tarde). Estes formulários tinham como objectivo fazer um levantamento de informação, nos níveis legal e socio-económico, relativa ao fenómeno do trabalho doméstico. Numa segunda etapa (estudo de campo - parte I) realizou-se uma análise qualitativa do fenómeno ${ }^{3}$ e, a partir dos resultados obtidos, construíram-se os instrumentos para a realização de uma análise extensiva. A análise qualitativa anteriormente referida incluiu a realização de vinte e nove entrevistas a empregadores(as) e trabalhadores(as) domésticos (de nacionalidade portuguesa e imigrantes de diversas nacionalidades) na zona de Lisboa e Vale do Tejo e no arquipélago dos Açores, na ilha de São Miguel, a transcrição integral das entrevistas e a elaboração de diários de campo. Concluída a fase qualitativa, foi elaborado um inquérito por questionário (estudo de campo - parte II) com a finalidade de avaliar a validade da investigação qualitativa e a possibilitar inferências mais gerais sobre a realidade do trabalho doméstico

\footnotetext{
2 Regulamento da Formação Avançada e Qualificação de Recursos Humanos consultado a 13 de Novembro de 2009, disponível em http://alfa.fct.mctes. pt/apoios/bolsas/regulamento. phtml.

${ }^{3}$ Esta análise, no âmbito do Projecto, foi realizada apenas em Portugal.
} 
em Portugal. ${ }^{4}$ A terceira etapa consiste na análise comparativa dos dados recolhidos em cada país e, por fim, na quarta etapa, divulgar-se-á os resultados do projecto e distribuir-se-á um conjunto de brochuras aos membros da população estudada com o objectivo de os informar sobre os seus direitos.

As Bolsas de Integração na Investigação (BII) foram-nos atribuídas numa fase em que já se encontravam realizadas as primeiras análises comparativas e se iniciava a análise qualitativa do objecto (estudo de campo - parte I). Desta forma, as nossas tarefas incidiram, essencialmente, nos seguintes domínios: estudo de campo parte I (transcrição de dez entrevistas, elaboração de dois diários de campo, mapeamento de oito entrevistas); realização de um estudo sobre as empresas de contratação de trabalho doméstico ${ }^{5}$, e estudo de campo - parte II (aplicação de onze questionários).

O projecto de investigação "Trabalho Doméstico e Trabalhadores Domésticos: Perspectivas Interdisciplinares e Comparadas”, no contexto nacional, está a ser desenvolvido no DINÂMIA (Centro de Estudos sobre a Mudança Socioeconómica), sendo que este foi fundado em 1989 e se encontrasediado no Instituto Superior de Ciências do Trabalho e da Empresa - Instituto Universitário de Lisboa (ISCTE IUL).

Esta organização, sem fins lucrativos, tem por finalidade o desenvolvimento de projectos na área das Ciências Sociais, dando-se especial enfoque a uma abordagem multidisciplinar. As duas grandes temáticas são "Regulação, governança e políticas públicas” e "Dinâmicas socioeconómicas e desenvolvimento sustentável”. As principais linhas de investigação são as seguintes:

- Trabalho e mudança organizacional;

- Inovação e conhecimento;

- Desenvolvimento do território e planeamento;

- Instituições e comportamento;

- Regulação, globalização e Europa. ${ }^{6}$

É na linha de investigação “Trabalho e mudança organizacional” que se enquadra o projecto em que nos inserimos. Esta linha de investigação tem por objectivo "melhorar o conhecimento acerca das mudanças no trabalho e nas organizações no contexto da crescente internacionalização” e explora as seguintes vertentes:

- Evolução das competências em determinados sectores de actividade;

- Políticas e práticas de gestão dos recursos humanos nas médias empresas;

\footnotetext{
${ }^{4}$ É nesta fase que, actualmente, se encontra o projecto.

${ }^{5}$ Esta tarefa foi realizada entre o final da primeira parte do estudo de campo e a segunda parte e inicialmente não encontrava prevista.

6 http://dinamia.iscte.pt/index.php?option=com_content\&task=view\&id=25\&/temid=177, consultado a 13 de Novembro de 2009.
} 
- Evolução das relações laborais em Portugal no contexto da União Europeia;

- Evolução da militância sindical;

- Adaptabilidade dos trabalhadores no enquadramento da "flexissegurança”;

- Análise teórica das motivações e incentivos subjacentes à criação e partilha de inovação. ${ }^{7}$

Este texto irá estruturar-se segundo os seguintes tópicos: (1) processos de aquisição de capital científico e (2) imbricamento entre o sistema social DINÂMIA e o sistema psíquico do sujeito. No primeiro, com base na leitura da obra Para uma Sociologia da Ciência, far-se-á um trabalho de objectivação do sujeito da objectivação em dois níveis, a saber, a objectivação da posição no espaço social global do sujeito - a sua trajectória social - e a objectivação da posição ocupada pelo mesmo no campo científico (Bourdieu, 2004: 130). No segundo analisar-se-á o DINÂMIA enquanto organização e sistema social e o imbricamento desta organização com as nossas experiências individuais de socialização, tendo presente o facto de que este imbricamento interage com os nossos habitus estruturantes e estruturados. Esta última secção terá como referência principal o texto Os direitos subjectivos na teoria dos sistemas de Niklas Luhmann (Guibentif, 2009). ${ }^{8}$

\section{NOTA TEÓRICA}

O objecto em análise - as nossas experiências de integração na investigação - afigura-se problemático uma vez que o objecto empírico consiste na nossa subjectividade face às diferentes experiências vividas aquando da realização das tarefas que nos foram atribuídas. Por esse motivo optámos por realizar uma nota teórica que, na medida em que nos proporciona um maior distanciamento face ao objecto, permite-nos realizar uma análise mais consciente e objectiva.

\subsection{Processos de aquisição de capital científico}

As nossas auto-análises baseiam-se, respectivamente, nas nossas trajectórias sociais em termos de aquisição de capital social adquirido ao longo do processo de aquisição do capital científico. O capital social é entendido, neste contexto, como o conjunto de agentes sociais - inseridos num dado campo e dotados de habitus específicos desse campo - com os quais nos pudemos relacionar ao longo dos nossos processos de formação académica. Essas interacções foram moldando, ao longo do tempo, as nossas disposições e os nossos códigos de interpretação da realidade. Em suma, o processo de

\footnotetext{
${ }^{7}$ http://dinamia.iscte. pt/index.php?option=com_content\&task=category\&sectionid=20\&id=92\&l temid=1, consultado a 13 de Novembro de 2009.

${ }^{8}$ É necessário evidenciar o facto de, apesar da pertinência da bibliografia seleccionada, existirem outras obras que certamente dariam um contributo muito interessante para a análise que aqui desenvolvemos.
} 
aquisição de capital científico - capital obtido através de um processo de aquisição de capital social exerceu sobre os nossos habitus um efeito de estruturação que nos permitiu entrar e movimentarmonos em subcampos diferenciados do campo científico. O capital científico, conquistado da forma anteriormente enunciada, "é uma espécie particular de capital simbólico, capital fundado no conhecimento e no reconhecimento. Poder que funciona como forma de crédito, pressupõe a confiança ou a crença dos que o suportam porque estão dispostos (pela sua formação e pelo próprio facto de pertença ao campo) a atribuir crédito. A estrutura de distribuição do capital determina a estrutura do campo, ou seja, as relações de força entre os agentes científicos: a posse de uma quantidade (logo, de uma parte) importante de capital confere poder sobre o campo, portanto, sobre os agentes comparativamente menos dotados de capital (e sobre o requisito de admissão no campo) e comanda a distribuição das hipóteses de lucro.” (Bourdieu, 2004: 53). Passamos, então, a uma análise individualizada das nossas trajectórias sociais e, consequentemente, a um diagnóstico do (incipiente) capital científico até agora acumulado por cada uma de nós:

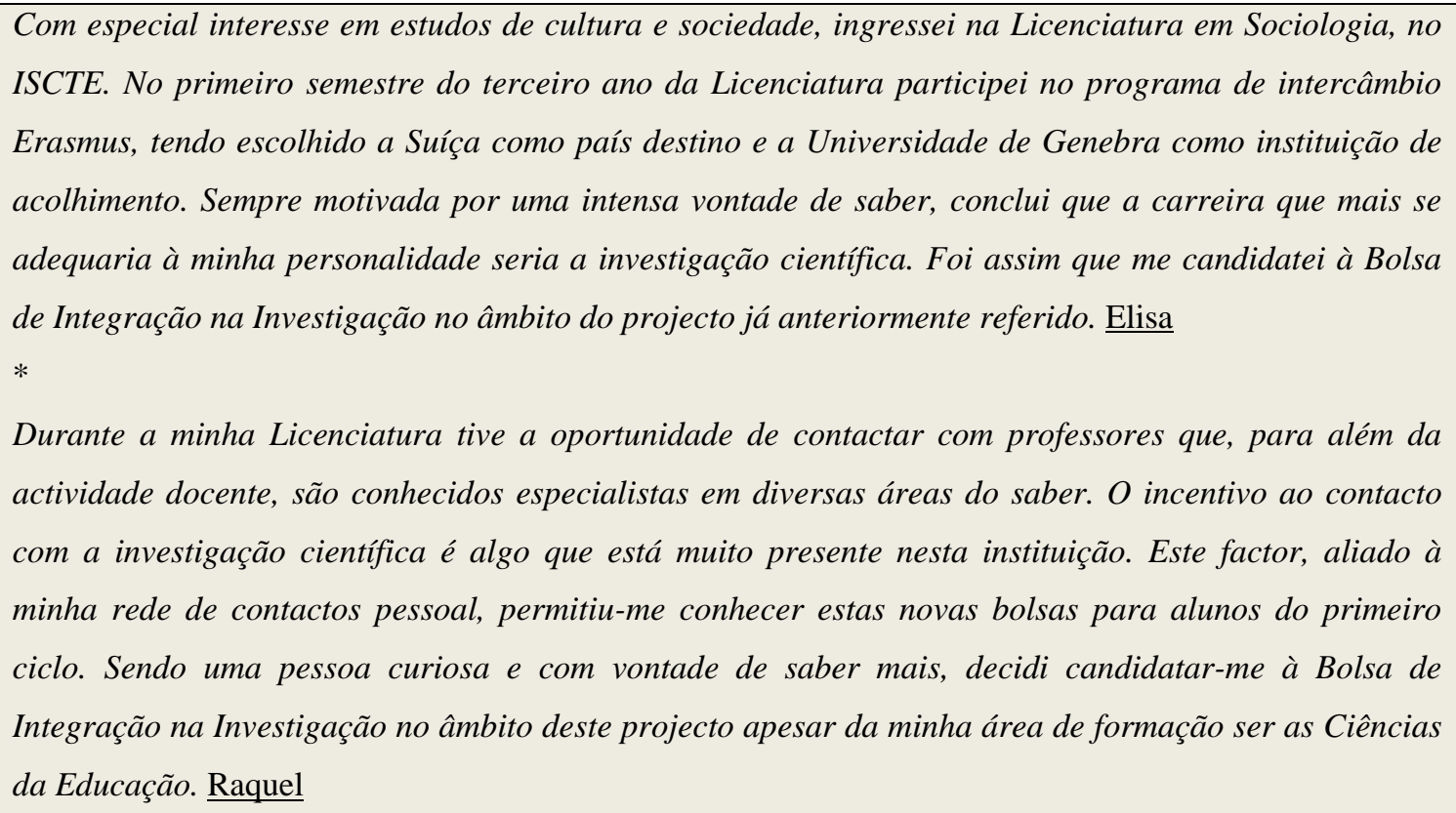

\section{Relatos no1}

Os capitais científicos por nós adquiridos no âmbito das nossas formações académicas - assim como os respectivos capitais sociais - permitiram-nos adquirir novos capitais sociais através dos processos de integração na investigação por nós experienciados e das socializações que lhes subjazem. Estes processos decorreram numa lógica dialéctica de imbricamento entre a nossa subjectividade - ou, por outras palavras, entre nós, seres físicos e sistemas psíquicos - e o DINÂMIA enquanto organização - ou, por outras palavras, enquanto sistema social. 


\subsection{Imbricamento entre sistema social DINÂMIA e o sistema psíquico do sujeito}

A partir da leitura do texto Os direitos subjectivos na teoria dos sistemas de Niklas Luhmann (Guibentif, 2009), partimos da tese de que existe uma relação de complementaridade entre sistemas psíquicos e sistemas sociais. Procedemos, por agora, a uma explicação destes conceitos para, numa fase posterior da presente discussão, expor o modo como se interligam.

$\mathrm{O}$ autor estabelece um paralelismo entre o conceito sistema psíquico e consciência ou, mais especificamente, entre sistema psíquico e o sujeito (objectivado e objectivante). O sistema psíquico distingue-se do ambiente a partir de uma dupla operação de distinção, a saber, a combinação entre a hetero-referência e a auto-referência. A primeira implica a percepção do objecto e a segunda, sobre uma percepção anterior desse objecto, implica a sua categorização.

\footnotetext{
"Para concretizar este modelo no domínio óptico: a visão de contornos diferentes dos vistos inicialmente obriga a repensar a qualificação; a intuição de uma qualificação um pouco diferente sugere outra visão. Num caso como no outro, a diferença é percepcionada porque se distinguiu o percepcionado (hetero-referência) da qualificação (auto-referência) e que estes dois elementos foram relacionados numa operação de comparação (onde se reencontra o paradoxo da unidade da diferença, frequentemente referido por Luhmann)” (Guibentif, 2009: 6).
}

É através desta dupla operação que se opera a distinção entre sistema psíquico e ambiente e, da mesma maneira, é nesta distinção que o sistema psíquico se constitui enquanto sujeito (objectivado e objectivante) dotado da capacidade de observar e compreender os mecanismos de constituição e funcionamento da própria consciência.

Os sistemas sociais distinguem-se entre si através da comunicação. A comunicação, enquanto operação básica dos sistemas sociais, efectua-se através de um médium, nomeadamente, o sentido associado aos símbolos comunicados. A comunicação desdobra-se em três componentes, nomeadamente, a informação, a expressão e a compreensão.

Os sistemas sociais podem assumir várias formas, sendo a organização uma delas. A organização, neste sentido, consiste num sistema social que compreende um número de sistemas psíquicos igual ou superior à unidade e um conjunto partilhado de símbolos dotados do mesmo sentido. O sentido atribuído a este conjunto partilhado de símbolos difere, em maior ou menor grau, segundo os sistemas sociais. Deste modo, as organizações, enquanto sistemas sociais dotados de um conjunto partilhado de símbolos (sendo que este conjunto partilhado de símbolos pressupõe um código específico de interpretação da realidade, ou, por outras palavras, uma modalidade distinta de autoreferência), funcionam como instituições mediadoras entre sistemas psíquicos dotados de códigos de 
interpretação da realidade incompatíveis entre si, permitindo o estabelecimento de um processo comunicacional que, à partida, seria improvável. Por outro lado, quando um dado número (superior à unidade) de sistemas psíquicos se concentra no mesmo sistema social, ou na mesma organização, existe uma partilha de símbolos e, consequentemente, um código comum de interpretação da realidade. Os sistemas psíquicos (ou os sujeitos) integrados no mesmo sistema social (ou organização) incorporam combinações específicas de capital social e capital científico através das comunicações entre eles estabelecidas (sendo que, neste sentido, o processos comunicacionais se desenrolam numa lógica de cooperação e não de competição). Esta dinâmica de comunicação intra-organizacional implica um fortalecimento da organização enquanto sistema social face a outras organizações, assim como um fortalecimento dos sujeitos envolvidos em processos comunicacionais com o exterior.

Passamos, agora, a descrever as principais tarefas por nós executadas, dividindo-as em três grupos: Estudo de campo - Parte I, Estudo sobre empresas de contratação de trabalho doméstico e, por fim, Estudo de campo - Parte II. Nesta secção do texto faremos uma descrição pormenorizada das tarefas por nós realizadas procurando, da mesma maneira, dar ao leitor uma compreensão mais aprofundada das nossas experiências de integração no DINÂMIA - aqui entendido enquanto sistema social ou organização, dotado das lógicas de funcionamento que lhe são intrínsecas, nomeadamente, aquelas que se referem à sua imbricação com os sistemas psíquicos nele integrados - através da inclusão de diários de campo individuais relativos a cada grupo de tarefas. Concluída esta tarefa descritiva, procuraremos realizar um balanço final, com base nos contributos teóricos anteriormente mencionados e discutidos, das nossas experiências de integração na investigação do trabalho doméstico.

\section{PRINCIPAIS TAREFAS}

\subsection{Estudo de campo - Parte I}

As primeiras tarefas que nos foram atribuídas consistiram nas transcrições integrais de entrevistas semi-directivas e aprofundadas realizadas a trabalhadoras domésticas e empregadoras, de diferentes nacionalidades, em Lisboa e Vale do Tejo e na ilha de São Miguel, situada no arquipélago dos Açores. Estas tarefas foram executadas durante um período de quatro meses, entre 19 de Dezembro de 2008 e 12 de Março de 2009.

Transcrevemos quatro entrevistas realizadas a empregadoras e cinco entrevistas realizadas a trabalhadoras domésticas sendo que, no conjunto das empregadoras, duas eram portuguesas, uma era americana e uma era holandesa e, no conjunto das trabalhadoras domésticas, três eram de nacionalidade portuguesa, uma era de nacionalidade ucraniana e uma era de nacionalidade brasileira. 
Apresentamos, de seguida, dois diários de campo individualizados relativos ao processo de auto-referência presente na execução desta tarefa.

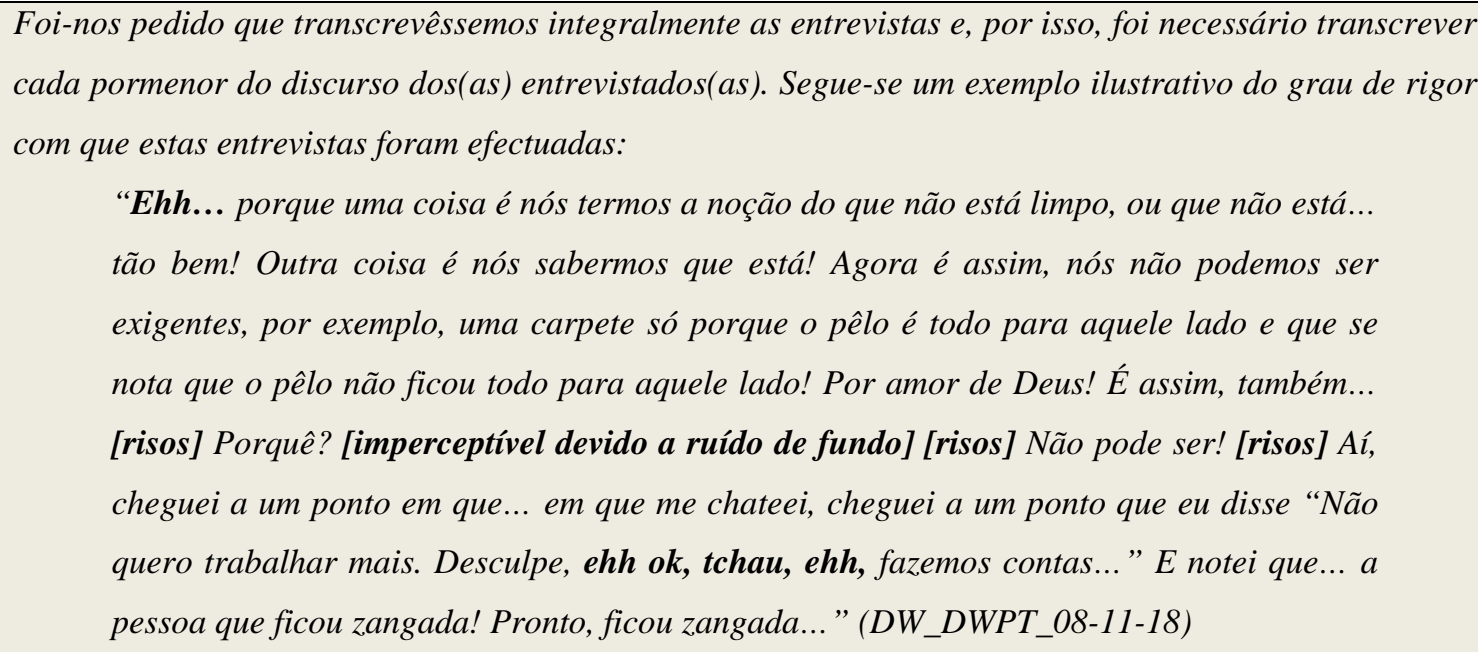
cada pormenor do discurso dos(as) entrevistados(as). Segue-se um exemplo ilustrativo do grau de rigor com que estas entrevistas foram efectuadas:

"Ehh... porque uma coisa é nós termos a noção do que não está limpo, ou que não está... tão bem! Outra coisa é nós sabermos que está! Agora é assim, nós não podemos ser exigentes, por exemplo, uma carpete só porque o pêlo é todo para aquele lado e que se nota que o pêlo não ficou todo para aquele lado! Por amor de Deus! É assim, também... [risos] Porquê? [imperceptível devido a ruído de fundo] [risos] Não pode ser! [risos] Aí, cheguei a um ponto em que... em que me chateei, cheguei a um ponto que eu disse "Não quero trabalhar mais. Desculpe, ehh ok, tchau, ehh, fazemos contas...” E notei que... a pessoa que ficou zangada! Pronto, ficou zangada...” (DW_DWPT_08-11-18)

A minha primeira experiência no âmbito da realização deste tipo de tarefa foi relativamente atribulada devido, sobretudo, a dois motivos: a minha própria inexperiência e a qualidade da gravação. Com efeito, esta entrevista foi realizada num café e foi perturbada por vários ruídos de fundo, nomeadamente, uma motosserra a trabalhar junto da esplanada, a barulho provocado pela máquina do café, um grupo a cantar os parabéns e o burburinho constante próprio de um espaço público de convívio. Esta experiência fez-me evoluir no sentido em que pude treinar a minha capacidade de concentração e compreensão do discurso (com tendência a prestar atenção isoladamente a cada palavra, passei a captar o sentido do discurso na sua globalidade). Assim, todas as transcrições que se seguiram me pareceram bastante mais fáceis. Elisa

*

Ao longo da minha Licenciatura tive a oportunidade de realizar entrevistas e de transcrever as mesmas. Pensei estar familiarizada com este tipo de tarefa quando no Projecto "Trabalho Doméstico e Trabalhadores Domésticos: Perspectivas Interdisciplinares e Comparadas" me pediram para transcrever quatro entrevistas. No entanto, a experiência revelou-se diferente. As entrevistas realizadas tinham cerca de uma hora e, em alguns casos, mais de uma hora. Deste modo, as transcrições demoravam vários dias até estarem concluídas o que tornou esta tarefa muito desgastante psicologicamente. Porém, o elevado grau de rigor das transcrições revelou-se uma mais-valia para mim, enquanto estudante universitária, uma vez que me permitiu ganhar maior destreza na transcrição de entrevistas e também me permitiu estar mais sensível à complexidade do discurso dos(as) entrevistados(as). Raquel

\section{Relatos $\mathrm{n} \div 2$}

A realização e a transcrição integral das entrevistas foram acompanhadas pela redacção de diários de campo, elaborados a partir da observação destas enquanto situações de interacção social, espacial e temporalmente delimitadas e condicionadas. Apenas uma de nós teve a oportunidade de 
realizar este tipo de tarefa. Foram, então, redigidos dois diários de campo a partir de duas entrevistas realizadas, respectivamente, a uma empregadora portuguesa e a uma trabalhadora doméstica de nacionalidade também portuguesa. Estas tarefas foram levadas a cabo durante um período de aproximadamente um mês, entre os dias 5 de Fevereiro e 26 de Fevereiro de 2009. Apresentamos, seguidamente, um breve relato das experiências de realização destas tarefas:

Tive a oportunidade de assistir a duas entrevistas, sendo que a primeira foi realizada a uma
empregadora no seu local de trabalho - um escritório de advocacia situado no centro de Lisboa -e a
segunda foi realizada a uma trabalhadora doméstica também no seu local de trabalho - uma residência
de estudantes perto de Entre Campos. Tendo sido o primeiro diário de campo de uma entrevista que
alguma vez havia elaborado, houve um contratempo que considero ser relevante assinalar. À medida
que a entrevistada respondia às questões colocadas pela entrevistadora, eu apontava num caderno
todos os aspectos que me pareciam relevantes para, posteriormente, os incluir no diário de campo. Fui-
me apercebendo, no entanto, que o ruído provocado pelo roçar da caneta no papel estava a perturbar a
qualidade da gravação. Senti também que o facto de estar constantemente a tirar notas e não a
estabelecer uma relação empática com a entrevistada poderia ser confundido com uma forma de
indelicadeza. Foi quando parei de escrever e comecei a escutar atentamente a entrevistada que
compreendi que a melhor estratégia a adoptar seria observar discretamente o espaço que me rodeava, a
postura da entrevistada e escutar empaticamente aquilo que ela tinha para dizer. Ao confiar mais na
minha memória do que nos meus apontamentos descobri também que era benéfico redigir o diário de
campo logo a seguir à realização da entrevista. Foram estes os princípios que procurei aplicar na
observação que se seguiu. Elisa

\section{Relato $n \div 3$}

O último grupo de tarefas realizadas no âmbito da fase qualitativa do projecto consistiu na análise das informações recolhidas através das entrevistas. Esta análise foi elaborada a partir de dois quadros, a saber, um quadro adaptado a trabalhadoras domésticas portuguesas e um quadro adaptado a trabalhadoras domésticas imigrantes.

As dimensões de análise são as seguintes:

- Dados sociográficos;

- Percurso profissional;

- Imigração, percurso e adaptação ${ }^{9}$;

- Questões legais e salariais;

- Relação laboral e primeira experiência;

\footnotetext{
${ }^{9}$ Encontra-se presente apenas no quadro relativo às trabalhadoras domésticas imigrantes.
} 
- Representações sobre o trabalho doméstico;

- Violação dos direitos.

Apresentamos seguidamente dois relatos individuais relativos às diferentes experiências no âmbito da realização destas tarefas.

\begin{abstract}
Foi-me atribuída a tarefa de mapear quatro entrevistas realizadas a trabalhadoras domésticas portuguesas. Realizei o mapeamento em quatro etapas. Numa primeira etapa estudei as tabelas de preenchimento e as respectivas categorias, tendo constatado que estas categorias se encontravam assinaladas a cores diferentes. Numa segunda fase escutei atentamente os discursos para obter uma compreensão mais aprofundada dos seus sentidos. Numa terceira fase destaquei as partes relevantes para cada categoria com a cor respectiva. Numa quarta fase inseri a informação relevante para cada categoria no respectivo campo da tabela. Interpretei esta tarefa como uma forma de sintetizar a informação recolhida a partir da realização das entrevistas. Elisa

$*$

Esta tarefa, apesar de ser diferente daquilo a que estou habituada a fazer, não se revelou particularmente difícil. Durante a minha Licenciatura aprendi a construir uma tabela que utilizo para realizar a análise de conteúdo de entrevistas. Nessa tabela constam os seguintes aspectos: categorias, subcategorias e unidades de registo. As categorias representam o principal tema de conversa; as subcategorias consistem em pequenas divisões do tema em questão e as unidades de registo correspondem às citações do(a) entrevistado(a) que evidenciam a abordagem ao tema em análise. Do meu ponto de vista, a execução da análise de entrevistas e desta tarefa é semelhante. No entanto, os quadros utilizados para o mapeamento das entrevistas são bastante mais detalhados o que, por vezes, dificultou o preenchimento dos mesmos, ou seja, tornou-se complicado encontrar informação que completasse todos os campos de informação. Contudo, foi uma tarefa importante para mim porque me permitiu conhecer uma nova técnica de sistematização da informação das entrevistas. Raquel
\end{abstract}

\title{
Relato no4
}

\subsection{Estudo sobre empresas de contratação de trabalho doméstico}

Realizámos um pequeno estudo sobre as empresas de contratação de trabalho doméstico em Portugal pelo seguinte motivo: tem-se verificado um aumento exponencial deste tipo de empresas que, procurando transmitir uma imagem de integridade e confiança, funcionam de acordo com dinâmicas ocultas. O propósito deste estudo foi, precisamente, obter informações que não poderiam ser obtidas por parte de uma equipa de investigação científica. ${ }^{10}$ Pretendíamos, consequentemente, averiguar

\footnotetext{
${ }^{10}$ A estratégia utilizada, como se verá mais adiante, foi a encarnação de uma personagem fictícia, representando o papel de potencial cliente.
}

DINÂMIA - Centro de Estudos sobre a Mudança Socioeconómica

ISCTE-IUL - Av. das Forças Armadas, 1649-026 Lisboa, PORTUGAL

Tel. 217938638 Fax. 217940042 E-mail: dinamia@iscte.pt www.dinamia.iscte.pt 
quaisquer discrepâncias existentes entre o discurso destas empresas e a realidade social observada aquando do trabalho de campo junto dos(as) trabalhadores(as) domésticos(as) e patrões(oas).

Partimos, em primeira instância, de uma base de dados construída a partir dos nomes e respectivos contactos e websites. Esta tarefa foi realizada ao longo de três etapas: (1) análise de conteúdo dos websites das empresas de contratação de trabalho doméstico, (2) contacto telefónico com cada empresa e (3) elaboração de um relatório final.

A primeira etapa caracteriza-se por uma análise de conteúdo dos websites em duas dimensões analíticas, nomeadamente, a dimensão visual e a dimensão discursiva. A dimensão visual contém as subdimensões número de separadores, catalogação de separadores, cores, logótipo e imagens e a dimensão discursiva contém as subdimensões objectivos, público, serviços e competências.

Na segunda etapa preparámos um conjunto de documentos de apoio aos contactos telefónicos, nomeadamente, um guião com as questões a colocar e as respostas esperadas e um documento com as informações relativas à personagem a encarnar (nome, idade, actividade profissional, morada, número de telefone, número de assoalhadas, agregado familiar e preferência por serviço doméstico interno ou externo), assim como as especificidades por empresa (área de actuação, morada da personagem a encarnar, nacionalidade da trabalhadora doméstica a contratar e horário pretendido). Após a elaboração destes documentos realizámos os contactos telefónicos.

A terceira etapa consistiu na redacção de um relatório final reconstituindo os procedimentos efectuados para levar a cabo o estudo, procurando, da mesma maneira, efectuar uma análise das empresas contactadas que enquadrasse pertinentemente as informações recolhidas aquando da realização da análise de conteúdo e as informações recolhidas aquando da realização dos telefonemas.

Apresentamos, de seguida, relatos individuais que dão conta do modo como percepcionámos e interpretámos esta experiência.

Para elaborar a análise de conteúdo dos websites das empresas de contratação de trabalho doméstico, parti de uma base de dados elaborada pela colega com quem escrevo o presente texto. Dividimos a base de dados em duas partes e, a partir dessa distribuição, comecei a pensar na melhor forma de realizar uma análise de conteúdo dos websites. Como nunca havia realizado uma tal tarefa, decidi fazer uma pesquisa na biblioteca do ISCTE de manuais que me pudessem auxiliar. Realizada a pesquisa e lidos alguns textos, continuava sem saber como me deveria guiar para realizar a tarefa. Compreendi, então, que deveria reflectir eu mesma em qual seria a melhor estratégia e cheguei à conclusão de que a construção de uma grelha de análise seria uma forma pertinente de organizar, sintetizar e quantificar a informação. A análise de conteúdo conheceu duas versões. A dificuldade que senti na elaboração da primeira prendia-se com um certo receio em analisar a informação recolhida devido ao risco de a distorcer com a minha própria subjectividade. Após a revisão desta versão senti-me mais à vontade para analisar a informação de acordo com um critério, a saber, os conhecimentos que já havia acumulado sobre o tema “igualdade de género". 
Os documentos de apoio ao contacto - uma grelha de perguntas e respostas esperadas (semelhante a um guião estruturado de entrevista) e um documento contendo informações sobre a personagem fictícia a encarnar - foram elaborados ao longo de três versões. As principais correcções centraram-se sobre o modo de colocar as questões e as informações relativas à personagem a encarnar.

A realização dos telefonemas não foi uma tarefa difícil para mim; com efeito, procurei que a personagem fictícia fosse relativamente parecida comigo para que a minha actuação fosse o mais convincente possível. Os principais obstáculos consistiram na reticência dos interlocutores em responder à última questão - esta visava a percentagem retida pela empresa da quantia mensal auferida pelo(a) trabalhador(a) doméstico(a) - e na tendência de alguns interlocutores para monopolizar a conversa e querer oficializar imediatamente o processo de contratação do(a) trabalhador(a) doméstico(a).

O relatório final incluiu todas estas etapas, sendo que as conclusões principais foram as seguintes: predominam atitudes discriminatórias com base na nacionalidade - traduzidas, sobretudo, em desigualdades salariais - e legitima-se uma imagem sexualizada e confinada ao espaço interior do género feminino. Elisa

A primeira etapa na realização desta tarefa foi a análise de conteúdo dos websites. Inicialmente, a minha análise esteve muito centrada em aspectos da dimensão visual, fazendo essencialmente uma descrição visual do website em estudo. Após esta primeira versão, com a ajuda das correcções e sugestões feitas pelos Bolseiros de Investigação (BI), consegui realizar uma análise crítica dos websites integrando vários elementos importantes que até então estavam esquecidos.

Para a realização dos telefonemas elaborei, inicialmente, um texto que simulava a minha conversa com as empresas em estudo. Este texto foi transformado num guião de apoio aos telefonemas. Ao longo da realização dos telefonemas o guião foi alterado, pois fui compreendendo qual seria a melhor maneira de abordar algumas das questões do meu guião. A principal dificuldade que tive prendeu-se com a encarnação da personagem fictícia que criei. Inicialmente os telefonemas eram efectuados na sala de trabalho dos bolseiros do DINÂMIA, mas devido à falta de experiência neste tipo de tarefa, preferi ausentar-me da sala e fazer os telefonemas sozinha, sem ninguém por perto. Deste modo consegui adaptar a personagem mais facilmente à minha própria personalidade. O relatório final que elaborei integrava a análise de conteúdo dos websites com respectiva apreciação crítica e expectativas em relação aos telefonemas. $\underline{\text { Raquel }}$

\section{Relatos no5}




\subsection{Estudo de campo - Parte II}

O último grupo de tarefas que executámos consistiu na aplicação de inquéritos por questionário. Este inquérito começou a ser elaborado em Março de 2009 e desde então já sofreu várias alterações. O principal objectivo deste inquérito é avaliar a validade da investigação qualitativa e a também recolher dados estatísticos sobre a realidade do trabalho doméstico em Portugal. Deste modo, este inquérito está a ser aplicado a trabalhadoras domésticas portuguesas e imigrantes. Seguidamente, apresentamos dois relatos pessoais sobre as experiências por nós vivenciadas:

Foi-me atribuída a tarefa de aplicar trinta questionários no espaço de tempo de aproximadamente um mês. Foi-me impossível cumprir este objectivo devido ao curto espaço de tempo estipulado para a realização da tarefa e devido à dificuldade em aceder à população visada. Pude, contudo, aplicar seis questionários. Os primeiros dois questionários foram preenchidos no dia 27 de Setembro, no Parque de Alvalade, durante uma celebração da Comunidade Romena. Os outros foram aplicados segundo o método de amostragem da bola-de-neve e, desse modo, foram aplicados a quatro membros de uma rede social constituída por indivíduos de nacionalidade brasileira. Ao realizar estas tarefas tive a oportunidade de compreender a maneira complexa como o questionário se encontrava estruturado e de adquirir maior destreza na aplicação do mesmo. Considero que estas tarefas foram importantes para a minha formação no sentido em que adquiri experiência neste método tão largamente utilizado pela comunidade científica dos sociólogos. Elisa

$*$

A aplicação de inquéritos foi uma tarefa totalmente nova para mim. Foi o último conjunto de tarefas realizado e para mim, o mais difícil. A principal aprendizagem que fiz com esta tarefa relaciona-se com a minha “orientação” metodológica, isto é, percebi, através da aplicação dos questionários, que me sinto mais confortável a trabalhar com abordagens de cariz mais qualitativo do que com abordagens de cariz mais quantitativo. O principal factor que fez com que me sentisse desmotivada para a realização desta tarefa foi o período de aplicação dos questionários, ou seja, a maior parte das vezes os questionários foram aplicados ao fim-de-semana o que me impedia de ter tempo para estudar e também para a minha vida pessoal. A minha primeira experiência na aplicação de questionários foi um pouco atribulada. Eu e os meus restantes colegas deslocamo-nos à Culturgest para a comemoração do $18^{\circ}$ aniversário da independência da Ucrânia. O evento estava muito bem estruturado o que deixava pouco tempo para intervalos, pois havia muitas actuações (música, dança, etc) e as pessoas que estavam presentes queriam divertir-se. A primeira dificuldade consistiu em encontrar senhoras disponíveis para responder ao inquérito. Conseguimos encontrar quatro pessoas: duas responderam ao inquérito na totalidade e as outras duas ficaram a meio, pois os maridos dessas mesmas senhoras eram extremamente possessivos e não estavam a gostar de ter alguém a fazer perguntas à sua esposa sobre a profissão da mesma. Os questionários aplicados depois deste dia não se revelaram particularmente difíceis, mas, no entanto, é um tipo de tarefa que não me motiva muito. Raquel

\section{Relatos n으}




\section{CONCLUSÃO}

A nossa experiência enquanto bolseiras do DINÂMIA - integradas no Projecto "Trabalho Doméstico e Trabalhadores Domésticos: Perspectivas interdisciplinares e comparadas” - foi importante para nós de duas maneiras.

Em primeiro lugar, pudemos adquirir capital social e capital científico na área da investigação sociológica. Este aspecto traduz-se numa maior disposição para a realização de investigação científica a um nível profissional.

Em segundo lugar, esta reconfiguração disposicional foi fomentada pela nossa integração enquanto sistemas psíquicos, ou sujeitos - na organização DINÂMIA. No plano dos nossos sistemas psíquicos, o facto de estarmos constantemente expostas a novos modos de trabalhar e a novas realidades sociais (tanto no campo do trabalho doméstico como no campo da produção científica) apurou e fez crescer a disposição que já tínhamos no sentido de realizar investigação científica. No interior do sistema social em que nos integrámos, através da distinção que o processo de comunicação acarreta e do capital científico por esse meio incorporado, experienciámos uma reconfiguração dos nossos habitus profissionais que certamente nos será favorável ao longo da nossa futura carreira.

\section{CRONOGRAMA}

\begin{tabular}{|c|c|c|c|c|c|c|c|c|c|c|c|c|}
\hline & Dez. & Jan. & Fev. & Mar. & Abr. & Mai. & Jun. & Jul. & Ago. & Set. & Out. & Nov. \\
\hline $\begin{array}{l}\text { Estudo de } \\
\text { campo - Parte } \\
\text { I }\end{array}$ & & & & & & & & & & & & \\
\hline $\begin{array}{l}\text { Estudo sobre } \\
\text { empresas de } \\
\text { trabalho } \\
\text { contratação de } \\
\text { trabalho } \\
\text { doméstico }\end{array}$ & & & & & & & & & & & & \\
\hline $\begin{array}{l}\text { Estudo de } \\
\text { campo - Parte } \\
\text { II }\end{array}$ & & & & & & & & & & & & \\
\hline
\end{tabular}




\section{BIBLIOGRAFIA}

BOURDIEU, Pierre (2004): Para uma Sociologia da Ciência, Edições 70, Lisboa.

GUIBENTIF, Pierre (2009): Os direitos subjectivos na teoria dos sistemas de Niklas Luhmann, manuscrito a publicar em Schwartz, Germano, Severo da Rocha, Leonel (orgs.), Luhmann e os direitos fundamentais, Porto Alegre (no prelo). 